\title{
An update on the prevalence of metabolic syndrome and its associated factors in rural northeast China
}

\author{
Shasha Yu', Xiaofan Guo', Hongmei Yang ${ }^{1}$, Liqiang Zheng ${ }^{2}$ and Yingxian Sun ${ }^{1 *}$
}

\begin{abstract}
Background: The last study reported the prevalence of Metabolic Syndrome (MetS) in rural Northeast China was conducted approximately ten years ago. We aimed to update the data on the prevalence and epidemiological features of MetS in rural Northeast China.

Methods: This survey was conducted from July 2012 to August 2013. In this study, a total of 11,496 residents from the rural Northeast China were randomly selected and examined. MetS was defined according to the ATPIII-modified criteria. Data regarding the demographic and lifestyle characteristics and the blood biochemical indexes of these participants were collected by well-trained personnel.

Results: The prevalence of MetS was 39.0\% and was more prevalent in women than in men (45.6\% vs. 31.4\%, $P<0.001)$. Elevated blood pressure was the most common metabolic disorder in both genders $(71.7 \%$ in males and $63.3 \%$ in females). Only $11.2 \%$ and $9.6 \%$ of males and females, respectively, in this study had no metabolic disorders. Multivariate logistic regression, after adjusting for possible confounders, revealed the following factors that increased the risk of MetS: being female, older age, having more than one child, a family income of $>20,000$ CNY per year, longer sleep duration ( $>9 \mathrm{~h} / \mathrm{d})$, chronic disease status, frequent consumption of beans or bean products and frequent tea drinking. Completion of education through middle school, moderate physical activity and smoking were correlated with lower rates of MetS.

Conclusion: The prevalence of MetS was high in the rural areas of China, especially among females. In addition to some of the more conventional risk factors associated with MetS, including age, sex, annual income and educational status, we also found that having more than one child and frequent consumption of tea and beans were risk factors for MetS, while smoking was a common factor among those that did not have MetS in rural Northeast China.
\end{abstract}

Keywords: Metabolic syndrome, Prevalence, Risk factor, Hypertension

\section{Background}

Metabolic syndrome (MetS), which is characterized by hyperlipidemia, elevated blood pressure, high fasting blood glucose and abdominal obesity, has become one of the greatest problems in the public healthcare system in both developed and developing countries. Previous studies have reported an increase in MetS in many developing countries, including the Philippines (19\%), Malaysia (24.2\%), India (28.8\%), Turkey (33.4\%), Iran (33.7\%), Venezuela

\footnotetext{
* Correspondence: sunyingxian12@aliyun.com

'Department of Cardiology, The First Hospital of China Medical University, 155 Nanjing North Street, Heping District, 110001 Shenyang, Liaoning, China Full list of author information is available at the end of the article
}

(31.2\%) and Brazil (25.4\%) [1]. Although the prevalence of MetS in China has not been extensively investigated, a relatively higher prevalence of MetS has been noted in several coastal and inland areas, including Sichuan (23.8\%), Shanghai (29.34\%), Beijing (23.2\%) and Guangdong $(26,7 \%)$ [2-4]. However, most of the studies examining the prevalence of MetS in China recruited participants from developed or urban areas. A nationwide population-based survey held in 2005 found that $57.01 \%$ of Chinese residents lived in rural areas. The prevalence of MetS is geographically varied in China [5]. People in rural areas have completely different lifestyles than those in urban areas. For

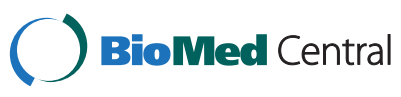

(C) 2014 Yu et al.; licensee BioMed Central Ltd. This is an Open Access article distributed under the terms of the Creative Commons Attribution License (http://creativecommons.org/licenses/by/4.0), which permits unrestricted use, distribution, and reproduction in any medium, provided the original work is properly credited. The Creative Commons Public Domain Dedication waiver (http://creativecommons.org/publicdomain/zero/1.0/) applies to the data made available in this article unless otherwise stated. 
example, adults in rural Northeast China prefer pickled cabbage and green Chinese onion dipped in soy sauce while those in urban areas do not.

Our previous study reported that $33.9 \%$ (men: 16.1\%; women: $47.8 \%$ ) of Han and $37.6 \%$ (men: $14.7 \%$; women: $55.0 \%$ ) of Mongolians had MetS, in accordance with the International Diabetes Federation definition for MetS [6]. Nevertheless, this study recruited only hypertensive residents and was performed approximately ten years ago. Rapid economic growth was seen in the rural areas of China followed by changes in dietary structure and lifestyle. We suspect that the prevalence and epidemiological features of MetS may have changed during the past ten years. Therefore, we performed this study to update the data regarding the prevalence of MetS and its risk factors in rural China in a large sample size of rural population during 2012-2013.

\section{Methods}

\section{Study population}

Liaoning Province is located in Northeast China. From January 2012 to August 2013, a representative sample of participants aged $\geq 35$ years was selected to characterize the prevalence, incidence and natural history of cardiovascular risk factors in rural areas of Liaoning Province. The study adopted a multi-stage, stratified, random-cluster sampling scheme. In the first stage, three counties (Dawa, Zhangwu and Liaoyang County) were selected from the eastern, southern and northern regions of Liaoning province. In the second stage, one town was randomly selected from each county (for a total of three towns). In the third stage, 8-10 rural villages from each town were randomly selected (for a total of 26 rural villages). Participants who were pregnant or had malignant tumors or mental disorders were excluded from the study. All the eligible permanent residents aged $\geq 35$ years from each village were invited to attend the study (a total of 14,016 participants). Of those, 11,956 participants agreed and completed the study to give a response rate of $85.3 \%$. The study was approved by the Ethics Committee of China Medical University (Shenyang, China). All procedures were performed in accordance with ethical standards. Written consent was obtained from all participants after they had been informed of the objectives, benefits, medical items and confidentiality agreement regarding their personal information. For participants who were illiterate, we obtained written informed consent from their proxies. In this report, we used only the data from participants who completed the study, which provided a final sample size of 11,496 (5309 men and 6187 women).

\section{Data collection and measurements}

Data were collected during a single visit to the clinic by cardiologists and trained nurses using a standard questionnaire in a face-to-face interview. Before the survey was performed, we invited all eligible investigators to attend an organized training session. The training included the purpose of this study, how to administer the questionnaire, the standard method of measurement, the importance of standardization and the study procedures. A strict test was administered after this training, and only those who scored perfectly on the test were accepted as investigators in this study. During data collection, our inspectors had further instructions and support.

Data regarding the demographic characteristics, lifestyle risk factors, dietary habits, family income and family history of chronic diseases were obtained during the interview using the standardized questionnaire. The study was guided by a central steering committee with a subcommittee for quality control. Educational level was assessed as completion of primary school or less, middle school or high school and higher. Self-reported sleep duration (including nocturnal and nap duration) was obtained from the questionnaire. The responses were categorized into four groups: $\leq 7,7-8,8-9$ and $>9 \mathrm{~h} / \mathrm{d}$. Family income was classified as $\leq 5000,5000-20,000$ and $>20,000 \mathrm{CNY} /$ year. The consumption of beans or bean products was assessed by the frequency eaten per week using the following scale: rarely $=0,2-3$ times $=$ 1 and $\geq 4$ times $=2$. The consumption of tea was also assessed by the frequency of consumption per day) using the following scale: no $=1$, rarely $=2,1-2$ times $=3$ and $\geq$ 3 times $=4$.

According to American Heart Association protocol, blood pressure (BP) was measured three times at 2-min intervals after at least $5 \mathrm{~min}$ of rest using a standardized automatic electronic sphygmomanometer (HEM-907; Omron), which had been validated according to the British Hypertension Society protocol [7]. The participants were advised to avoid caffeinated beverages and exercise for at least $30 \mathrm{~min}$ before the measurement. During the measurement, the participants were seated with their arms supported at the level of the heart. The mean of three BP measurements was calculated and used in all analyses.

Weight and height were measured to the nearest $0.1 \mathrm{~kg}$ and $0.1 \mathrm{~cm}$, respectively, with the participants wearing light-weight clothing and without shoes. Waist circumference (WC) was measured at the umbilicus using a non-elastic tape (to the nearest $0.1 \mathrm{~cm}$ ), with the participants standing at the end of normal expiration. Body mass index (BMI) was calculated as the weight in kilograms divided by the square root of the height in meters.

Fasting blood samples were collected in the morning after at least $12 \mathrm{~h}$ of fasting. Blood samples were obtained from an antecubital vein into Vacutainer tubes 
containing ethylenediaminetetraacetic acid (EDTA). Fasting plasma glucose (FPG), total cholesterol (TC), lowdensity lipoprotein cholesterol (LDL-C), high-density lipoprotein cholesterol (HDL-C), triglycerides (TGs) and other routine blood biochemical indexes were analyzed enzymatically using an autoanalyzer. All laboratory equipment was calibrated, and blinded duplicate samples were used for these analyses.

\section{Definitions}

According to the ATPIII-modified criteria, MetS was defined by the fulfillment of three or more the following criteria: 1) WC $\geq 90 \mathrm{~cm}$ in males and $\geq 80 \mathrm{~cm}$ in females; 2) $\mathrm{BP} \geq 130 / 85 \mathrm{mmHg}$ or currently taking hypertension medication; 3) serum glucose level $\geq 5.6 \mathrm{mmol} / \mathrm{L}$ or currently taking diabetes medication; 4) serum TGs $\geq$ $1.7 \mathrm{mmol} / \mathrm{L}$ or currently taking abnormal lipid medication; and 5) $\mathrm{HDL}-\mathrm{C}<1.03 \mathrm{mmol} / \mathrm{L}$ in males and $<1.29 \mathrm{mmol} / \mathrm{L}$ in females [8].

Physical activity included occupational and leisure-time physical activity. A detailed description of the methods for assessing physical activity has been presented elsewhere [9]. Occupational and leisure-time physical activity were merged and regrouped into the following three categories: 1) low-subjects who reported light levels of both occupational and leisure-time physical activity, 2) moderatesubjects who reported moderate or high levels of either occupational or leisure-time physical activity and 3) high-subjects who reported a moderate or high level of both occupational and leisure-time physical activity.

Dietary patterns were assessed by having participants recall the foods they had eaten during the previous year. The questionnaire included questions regarding the average consumption of several food items per week. The reported consumption was quantified approximately in terms of grams per week. Vegetable consumption was assessed on the following scale: rarely $=3,<1000 \mathrm{~g}=2,1000$ $2000 \mathrm{~g}=1, \geq 2000 \mathrm{~g}=0$, and meat consumption, including red meat, fish and poultry was assessed on the following scale: rarely $=0,<250 \mathrm{~g}=1,250-500 \mathrm{~g}=2$ and $\geq 500 \mathrm{~g}=3$ ). A special diet score (vegetable consumption score plus meat consumption score) was calculated for each participant (range 0-6). Higher values of the diet score indicated higher meat consumption, lower vegetable consumption and greater adherence to a Westernized diet, while lower values indicate adherence to the Chinese diet. Similar methods for calculating a diet score can be found in the ATTICA study [10].

\section{Statistical analysis}

Descriptive statistics were calculated for all the variables, including continuous variables (reported as mean values and standard deviations) and categorical variables (reported as numbers and percentages). The differences between the healthy and MetS groups were evaluated using the Student's t-test, ANOVA, non-parametric test or the $\chi^{2}$-test, as appropriate. Multivariate logistic regression analyses were used to identify independent factors of MetS, and odds ratios (ORs) and corresponding 95\% confidence intervals (CIs) were calculated. All the statistical analyses were performed using SPSS version 17.0 software, and $P$ values less than 0.05 were considered to be statistically significant.

\section{Results}

\section{Baseline characteristics of study population}

There were 5309 men and 6187 women aged $\geq 35$ years evaluated in this cross-sectional study. The mean age was 53 years. The baseline characteristics of the study subjects according to gender are shown in Table 1. The prevalence of MetS among all the study participants was $39 \%$ and was significantly higher in women $(45.6 \%)$ than in men $(31.4 \%)$.

\section{Prevalence of the MetS and its criteria}

The prevalence of MetS assessed as fulfilling three or more ATPIII-modified criteria, two or more criteria, one or more criteria and the individual metabolic syndrome criteria are shown in Figures 1 and 2. The overall prevalence of the MetS was 39.0\% (95\% CI: 37.6\%-40.4\%). A total of $89.6 \%$ (95\% CI: $89.0 \%-90.2 \%$ ) participants fulfilled at least one criterion, and $66.2 \%$ (95\% CI: $65.1 \%$ $67.3 \%)$ fulfilled two or more criteria. Women were more likely to have more than one or two metabolic disorders than men. Of the individual MetS criteria, high blood pressure had by far the highest prevalence, 67.2\% (95\% CI: 66.2\%-68.2\%). Increased fasting glucose had the second highest prevalence $47.1 \%$ (95\% CI: 45.8\%-48.4\%). The prevalence of abdominal obesity in the rural residents was 42.8\% (95\% CI: 41.4-44.2). High TGs and low HDL-C were of relatively lower prevalence, $32.1 \%$ (95\% CI: 30.6\%-33.6\%) and 29.6\% (95\% CI: 28.1\%-31.1\%), respectively. Impaired fasting glucose and elevated BP were more common in males, while females had higher prevalence of both abdominal obesity and low HDL.

\section{Prevalence of MetS based on demographics and socioeconomic status}

Selected risk factor characteristics of MetS for participants in this study are presented in Table 2 . The prevalence of MetS increased with age only in women. The lowest prevalence of MetS was found in the participants that had completed middle school and participated in regular moderate physical activity in either gender. The highest prevalence of MetS in females was found in those who had more than one child, an annual income $\leq 5000 \mathrm{CNY} /$ year, slept between 8-9 h/d, were not married, did not drink alcohol, had a diet score $<3$ 
Table 1 Characteristics of study population by gender in the rural population of Liaoning Province,China

\begin{tabular}{|c|c|c|c|c|}
\hline Variables & $\begin{array}{c}\text { Total } \\
\text { (11496) }\end{array}$ & $\begin{array}{c}\text { Men } \\
(5309)\end{array}$ & $\begin{array}{c}\text { Women } \\
(6187)\end{array}$ & $P$-value \\
\hline Age (year) & $53.82 \pm 10.57$ & $54.35 \pm 10.79$ & $53.37 \pm 10.35$ & $<0.001$ \\
\hline Ethnicity & & & & 0.327 \\
\hline Han & 10898(94.8) & $5027(94.7)$ & $5871(94.9)$ & \\
\hline Others $^{a}$ & $598(5.2)$ & $282(5.3)$ & $316(5.1)$ & \\
\hline Educational status & & & & $<0.001$ \\
\hline Primary school or below & $5726(49.8)$ & 2211(41.6) & $3515(56.8)$ & \\
\hline Middle school & $4687(40.8)$ & 2491(46.9) & 2196(35.5) & \\
\hline High school or above & 1083(9.4) & $607(11.4)$ & $476(7.7)$ & \\
\hline Physical activity & & & & $<0.001$ \\
\hline Light & $3421(29.8)$ & $1200(22.6)$ & $2221(35.9)$ & \\
\hline Moderate & $7429(64.6)$ & $3816(71.9)$ & $3613(58.4)$ & \\
\hline Severe & $646(5.6)$ & 293(5.5) & $353(5.7)$ & \\
\hline Annual income (CNY/year) & & & & 0.011 \\
\hline$\leq 5000$ & $1427(12.4)$ & $711(13.4)$ & $716(11.6)$ & \\
\hline $5000-20000$ & $6260(54.5)$ & 2845(53.6) & $3415(55.2)$ & \\
\hline$>20000$ & $3809(33.1)$ & 1753(33.0) & 2056(33.2) & \\
\hline Current smoking status (Yes) & $4056(35.3)$ & $3028(57.0)$ & 1028(16.6) & $<0.001$ \\
\hline Current drinking status (Yes) & 2593(22.6) & $2410(45.4)$ & 183(3.0) & $<0.001$ \\
\hline Marriage (Yes) & 10530(91.6) & 4896(92.2) & $5634(91.1)$ & 0.014 \\
\hline Diet score & $2.33 \pm 1.13$ & $2.55 \pm 1.10$ & $2.14 \pm 1.11$ & $<0.001$ \\
\hline Sleep duration $(\mathrm{h} / \mathrm{d})$ & $7.26 \pm 2.70$ & $7.42 \pm 1.63$ & $7.12 \pm 1.74$ & $<0.001$ \\
\hline SBP $(\mathrm{mmHg})$ & $141.76 \pm 23.47$ & $143.66 \pm 22.66$ & $140.14 \pm 24.04$ & $<0.001$ \\
\hline $\mathrm{DBP}(\mathrm{mmHg})$ & $82.05 \pm 11.77$ & $83.78 \pm 11.83$ & $80.57 \pm 11.52$ & $<0.001$ \\
\hline BMI $\left(\mathrm{kg} / \mathrm{m}^{2}\right)$ & $24.80 \pm 3.66$ & $24.73 \pm 3.54$ & $24.86 \pm 3.77$ & 0.058 \\
\hline WC (cm) & $82.43 \pm 9.83$ & $83.78 \pm 9.76$ & $81.28 \pm 9.74$ & $<0.001$ \\
\hline $\mathrm{TC}(\mathrm{mmol} / \mathrm{L})$ & $5.23 \pm 1.08$ & $5.16 \pm 1.04$ & $5.29 \pm 1.12$ & $<0.001$ \\
\hline TG (mmol/L) & $1.63 \pm 1.49$ & $1.66 \pm 1.66$ & $1.61 \pm 1.33$ & 0.123 \\
\hline LDL-C (mmol/L) & $2.92 \pm 0.82$ & $2.87 \pm 0.79$ & $2.97 \pm 0.84$ & $<0.001$ \\
\hline HDL-C (mmol/L) & $1.41 \pm 0.38$ & $1.41 \pm 0.42$ & $1.41 \pm 0.34$ & 0.679 \\
\hline FPG (mmol/L) & $5.90 \pm 1.64$ & $5.95 \pm 1.67$ & $5.86 \pm 1.60$ & 0.003 \\
\hline Cardiovascular disease $^{\mathrm{b}}$ & $1742(15.2)$ & $568(10.7)$ & 1174(19.0) & $<0.001$ \\
\hline Cerebrovascular disease $^{c}$ & 1012(8.8) & $490(9.3)$ & $522(8.5)$ & 0.068 \\
\hline Chronic kidney disease ${ }^{d}$ & 152(1.3) & $64(1.2)$ & $88(1.4)$ & 0.162 \\
\hline Metabolic syndrome & $4488(39.0)$ & $1668(31.4)$ & $2820(45.6)$ & $<0.001$ \\
\hline
\end{tabular}

Data are expressed as the mean \pm SD or as $\mathrm{n}(\%)$. Abbreviations: BMI body mass index, WC waist circumference, CNY China Yuan (1CNY = 0.161 USD), SBP systolic blood pressure, DBP diastolic blood pressure, $T C$ total cholesterol, TG triglyceride, $L D L-C$ low-density lipoprotein cholesterol, $H D L-C$ high-density lipoprotein

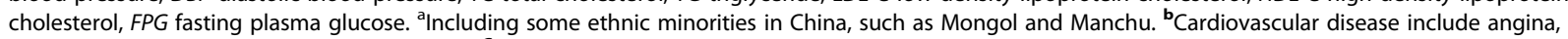
myocardia infarction, arrhythmia, heart failure. 'Cerebrovascular disease include cerebral hemorrhage, cerebral infarction, subarachnoid hemorrhage, Transient Ischemic Attack. ${ }^{\mathbf{d}}$ Chronic kidney disease nephritis, acute/chronic renal failure.

and with chronic diseases. While in men, those who were not married, were current smokers and drinkers, did not have chronic diseases and rarely consumed beans or bean products had a relatively lower risk of MetS. In all, individuals who drank 3-4 times/day had lowest risk of MetS.

\section{Factors associated with MetS}

We conducted a multiple logistic regression analysis of MetS and its associated factors. The results are also shown in Table 2. Individuals who were women, 45 years or older, with more than one children, an annual income $>20,000 \mathrm{CNY} /$ year, who slept longer ( $>9$ hours), 


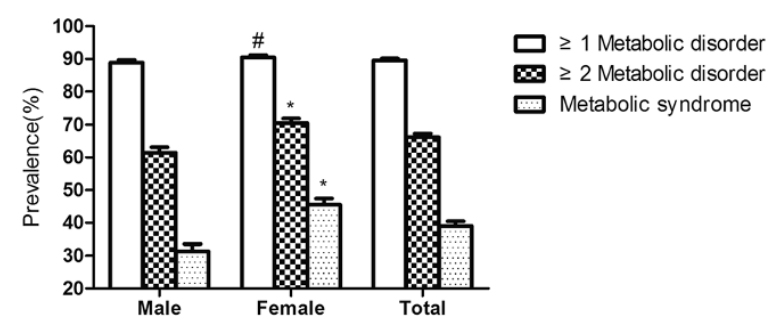

Figure 1 Prevalence of the metabolic syndrome and components among rural population of Liaoning Province,China. ${ }^{*} P<0.001$ for male:female difference in proportion; ${ }^{\#} P<0.05$ for male:female difference in proportion.

had cardiovascular or cerebrovascular disease, frequently consumed beans or bean products and frequently drank tea were more likely to have MetS. Current smoking status, graduating from at least middle school and taking part in moderate physical activity were found to be inversely associated with having MetS.

\section{Discussion}

The prevalence of MetS among rural Northeast Chinese participants was estimated at $39.0 \%$ (31.4\% for men and $45.6 \%$ for women) using the NCEP ATP III-modified criteria. A large proportion of participants (89.6\%) exhibited at least one metabolic disorder. Of the individual criteria for MetS, elevated blood pressure (67.2\%) and increased fasting glucose $(47.1 \%)$ were the most common, although the rest of the criteria were also common among participants. There were significantly gender differences in the prevalence of MetS and all the metabolic disorders, except hypertriglyceridemia. Females, of older age, with more than one child, who had an annual income $>20,000 \mathrm{CNY} /$ year, slept longer ( $>9$ hours), frequently consumed beans or bean products and frequently drank tea had a higher risk of having MetS, whereas those who graduated from middle school, participated in regular moderate physical activity and were current smokers had a decreased risk of having MetS.

The prevalence of MetS in our study was higher than that reported in other studies conducted in China [11-13]. Data from the China Health and Nutrition Surveys (CHNS) in 2009 showed that the prevalence of MetS was $18.2 \%$ and $10.5 \%$ using the definitions provided by the revised NCEP ATPIII and IDF, respectively [14]. WH Zhang and colleagues reported a prevalence of MetS of $25.3 \%$ in suburban Beijing during 2007-2008 [15]. Other studies of population-based studies estimated MetS prevalence among urban residents in China to be $26.04 \%$ to $32.5 \%$ in women and $17.91 \%$ to $35.1 \%$ in men using the IDF criteria [16,17]. Of note, however, was that the prevalence of MetS among the people of rural Northeast China was higher than those in some urban areas [18]. Furthermore, the prevalence in rural China was comparable to the prevalence in developed countries, including the U.S $(32.4 \%$ in women, $36.1 \%$ in men), Italy (15\% in men, $18 \%$ in women) and Canada (20.5\% in women, $17.8 \%$ in men) $[19,20]$. The high number of residents in rural Northeast China with hypertension may be a possible explanation for the high prevalence of MetS found in our study. We found that $33.7 \%$ and $51.1 \%$ of the participants had prehypertension and hypertension, respectively, which means that less than two individuals in ten had normal blood pressure. We compared the epidemiology of hypertension in rural Northeast China to other middle- or high-income countries, such as Singapore (58.6\%) and Russia (52\%), and found that they have similar rates of hypertension [21,22]. The high-salt, unhealthy diet consumed by many residents in rural Northeast China, such as commonly consumed pickled cabbage and spring onions dipped in soy sauce, elevates the blood pressure with resultant hypertension. Abdominal obesity seemed to be another important factor associated with the observed high incidence of MetS. In fact, the prevalence of MetS in our study decreased to

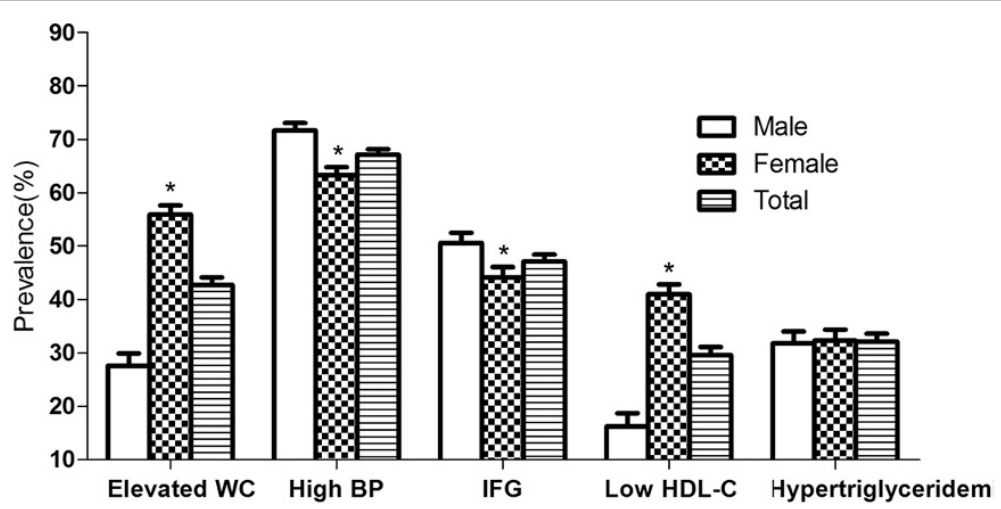

Figure 2 Prevalence of the metabolic components among rural population of Liaoning Province,China. Elevated WC:Elevated waist circumference; High BP:High Blood pressure; IFG:Increased fasting glucose; ${ }^{*} P<0.001$ for male:female difference in proportion. 
Table 2 Prevalence of MetS by levels of different status markers and multiple logistic regression analysis of MetS and the associated factors based on ATPIII-modified criteria in the rural population of Liaoning Province, China

\begin{tabular}{|c|c|c|c|c|c|c|c|c|c|}
\hline \multirow[b]{2}{*}{ Variables } & \multicolumn{3}{|c|}{ Male } & \multicolumn{3}{|c|}{ Female } & \multicolumn{3}{|c|}{ Total } \\
\hline & $\mathbf{N}$ & Pre (\%) & OR $(95 \% \mathrm{Cl})$ & $\mathbf{N}$ & Pre (\%) & OR $(95 \% \mathrm{Cl})$ & $\mathbf{N}$ & Pre (\%) & OR $(95 \% \mathrm{Cl})$ \\
\hline \multicolumn{10}{|l|}{ Age group } \\
\hline $35-44$ & 373 & 30.9 & 1.00(reference) & 411 & 26.9 & 1.00 (reference) & 784 & 28.7 & 1.00(reference) \\
\hline $45-54$ & 509 & 31.7 & $1.01(0.86,1.19)$ & 854 & 43.4 & $1.95(1.68,2.27)$ & 1363 & 38.1 & $1.49(1.33,1.67)$ \\
\hline $55-64$ & 530 & 32.6 & $0.99(0.83,1.19)$ & 1033 & 56.3 & $2.86(2.41,3.39)$ & 1563 & 45.2 & $1.81(1.60,2.05)$ \\
\hline$\geq 65$ & 873 & 29.3 & $0.77(0.61,0.97)$ & 522 & 61.1 & $3.20(2.56,3.99)$ & 778 & 45.0 & $1.64(1.40,1.91)$ \\
\hline \multicolumn{10}{|l|}{ Numbers of child } \\
\hline$\leq 1$ & 683 & 31.3 & 1.00 (reference) & 917 & 37.6 & 1.00 (reference) & 1600 & 34.6 & 1.00(reference) \\
\hline$>1$ & 985 & 31.5 & $1.03(0.90,1.17)$ & 1903 & 50.8 & $1.20(1.06,1.35)$ & 2888 & 42.0 & $1.13(1.04,1.24)$ \\
\hline \multicolumn{10}{|l|}{ Ethnicity } \\
\hline Han & 1588 & 31.6 & 1.00(reference) & 2690 & 45.8 & 1.00(reference) & 4278 & 39.3 & 1.00(reference) \\
\hline Others $^{a}$ & 80 & 28.4 & $0.82(0.62,1.08)$ & 130 & 41.1 & $0.91(0.72,1.17)$ & 210 & 35.1 & $0.87(0.73,1.05)$ \\
\hline \multicolumn{10}{|l|}{ Educational status } \\
\hline Primary school or below & 666 & 30.1 & 1.00(reference) & 1811 & 51.5 & 1.00(reference) & 2477 & 43.3 & 1.00(reference) \\
\hline Middle school & 765 & 30.7 & $0.98(0.86,1.13)$ & 824 & 37.5 & $0.84(0.74,0.95)$ & 1589 & 33.9 & $0.88(0.80,0.96)$ \\
\hline High school or above & 237 & 39.0 & $1.31(1.07,1.60)$ & 185 & 38.9 & $0.84(0.68,1.04)$ & 422 & 39.0 & $1.034(0.89,1.20)$ \\
\hline \multicolumn{10}{|l|}{ Physical activity } \\
\hline Light & 444 & 37.0 & 1.00(reference) & 1133 & 51.0 & 1.00(reference) & 1577 & 46.1 & 1.00(reference) \\
\hline Moderate & 1121 & 29.4 & $0.75(0.65,0.87)$ & 1505 & 41.7 & $0.87(0.77,0.97)$ & 2626 & 35.3 & $0.81(0.74,0.89)$ \\
\hline Severe & 103 & 35.2 & $0.96(0.72,1.26)$ & 182 & 51.6 & $1.19(0.94,1.51)$ & 285 & 44.1 & $1.06(0.89,1.27)$ \\
\hline \multicolumn{10}{|c|}{ Annual income (CNY/year) } \\
\hline$\leq 5000$ & 202 & 28.4 & 1.00(reference) & 378 & 52.8 & 1.00(reference) & 580 & 40.6 & 1.00(reference) \\
\hline 5000-20000 & 851 & 29.9 & $1.11(0.91,1.34)$ & 1563 & 45.8 & $0.99(0.83,1.18)$ & 2414 & 38.6 & $1.03(0.91,1.17)$ \\
\hline$>20000$ & 615 & 35.1 & $1.35(1.09,1.66)$ & 879 & 42.8 & $1.08(0.89,1.32)$ & 1494 & 39.2 & $1.19(1.03,1.36)$ \\
\hline \multicolumn{10}{|l|}{ Sleep duration $(\mathrm{h} / \mathrm{d})$} \\
\hline$\leq 7$ & 764 & 30.8 & 1.00(reference) & 1536 & 46.7 & 1.00(reference) & 2300 & 39.9 & 1.00(reference) \\
\hline 7-8 & 485 & 31.5 & $1.05(0.91,1.21)$ & 713 & 41.9 & $0.99(0.88,1.13)$ & 1198 & 37.0 & $1.01(0.92,1.11)$ \\
\hline 8-9 & 255 & 31.4 & $1.05(0.88,1.26)$ & 368 & 47.9 & $1.23(1.04,1.46)$ & 623 & 39.4 & $1.12(0.99,1.27)$ \\
\hline$>9$ & 164 & 34.5 & $1.23(0.99,1.52)$ & 203 & 47.1 & $1.23(0.99,1.52)$ & 367 & 40.5 & $1.18(1.02,1.37)$ \\
\hline \multicolumn{10}{|l|}{ Marriage } \\
\hline No & 111 & 26.9 & 1.00(reference) & 287 & 51.9 & 1.00(reference) & 398 & 41.2 & 1.00(reference) \\
\hline Yes $^{b}$ & 1557 & 31.8 & $1.18(0.93,1.51)$ & 2533 & 45.0 & $1.21(0.99,1.47)$ & 4090 & 38.8 & $1.10(0.95,1.28)$ \\
\hline \multicolumn{10}{|l|}{ Current smoking status } \\
\hline No & 783 & 34.3 & 1.00(reference) & 2363 & 45.8 & 1.00(reference) & 3146 & 42.3 & 1.00(reference) \\
\hline Yes & 885 & 29.2 & $0.78(0.69,0.89)$ & 457 & 44.5 & $0.78(0.67,0.90)$ & 1342 & 33.1 & $0.84(0.76,0.92)$ \\
\hline \multicolumn{10}{|l|}{ Current drinking status } \\
\hline No & 941 & 32.5 & 1.00(reference) & 2752 & 45.8 & 1.00(reference) & 3693 & 41.5 & 1.00(reference) \\
\hline Yes & 727 & 30.2 & $0.96(0.85,1.09)$ & 68 & 37.2 & $0.76(0.55,1.04)$ & 795 & 39.7 & $0.99(0.88,1.11)$ \\
\hline \multicolumn{10}{|l|}{ Cardiovascular disease $^{c}$} \\
\hline No & 1439 & 30.4 & 1.00 (reference) & 2139 & 42.7 & 1.00(reference) & 3578 & 36.7 & 1.00(reference) \\
\hline Yes & 229 & 40.3 & $1.44(1.19,1.74)$ & 681 & 58.0 & $1.40(1.21,1.61)$ & 910 & 52.2 & $1.44(1.28,1.60)$ \\
\hline \multicolumn{10}{|l|}{ Cerebrovascular disease $^{d}$} \\
\hline No & 1442 & 30.0 & 1.00(reference) & 2459 & 43.5 & 1.00 (reference) & 3901 & 37.3 & 1.00(reference) \\
\hline
\end{tabular}


Table 2 Prevalence of MetS by levels of different status markers and multiple logistic regression analysis of MetS and the associated factors based on ATPIII-modified criteria in the rural population of Liaoning Province, China (Continued)

\begin{tabular}{|c|c|c|c|c|c|c|c|c|c|}
\hline Yes & 215 & 43.9 & $1.78(1.45,2.18)$ & 357 & 68.4 & $1.94(1.58,2.38)$ & 572 & 56.5 & $1.82(1.58,2.09)$ \\
\hline \multicolumn{10}{|c|}{ Chronic kidney disease ${ }^{e}$} \\
\hline No & 1609 & 31.0 & 1.00(reference) & 2690 & 44.9 & 1.00(reference) & 4299 & 38.5 & 1.00(reference) \\
\hline Yes & 30 & 46.9 & $1.55(0.93,2.61)$ & 52 & 59.1 & $1.09(0.68,1.73)$ & 82 & 53.9 & $1.36(0.96,1.92)$ \\
\hline \multicolumn{10}{|c|}{ Diet score } \\
\hline$<3$ & 695 & 31.3 & 1.00(reference) & 1744 & 47.8 & 1.00(reference) & 2439 & 41.6 & 1.00(reference) \\
\hline$\geq 3$ & 973 & 31.5 & $1.01(0.89,1.15)$ & 1076 & 42.3 & $0.91(0.82,1.02)$ & 2049 & 36.4 & $0.97(0.89,1.05)$ \\
\hline \multicolumn{10}{|c|}{$\begin{array}{l}\text { Beans or Bean products intake } \\
\text { (Frequence/week) }\end{array}$} \\
\hline Rarely & 501 & 28.4 & 1.00 (reference) & 1251 & 45.4 & 1.00 (reference) & 1752 & 38.8 & 1.00(reference) \\
\hline 2-3times & 925 & 32.0 & $1.17(1.02,1.33)$ & 1262 & 45.3 & $1.03(0.92,1.16)$ & 2221 & 38.7 & $1.09(0.99,1.18)$ \\
\hline$\geq 4$ times & 242 & 36.7 & $1.42(1.17,1.73)$ & 273 & 47.5 & $1.12(0.92,1.36)$ & 515 & 41.7 & $1.24(1.09,1.43)$ \\
\hline \multicolumn{10}{|c|}{ Tea intake (Frequence/day) } \\
\hline No & 788 & 29.7 & 1.00(reference) & 2160 & 46.5 & 1.00(reference) & 2948 & 40.4 & 1.00(reference) \\
\hline rarely & 458 & 33.4 & $1.20(1.04,1.38)$ & 393 & 43.0 & $1.08(0.93,1.26)$ & 851 & 37.2 & $1.11(1.00,1.23)$ \\
\hline 1-2 times & 356 & 32.9 & $1.21(1.03,1.42)$ & 245 & 43.4 & $1.03(0.85,1.24)$ & 601 & 36.5 & $1.11(0.99,1.26)$ \\
\hline 3-4 times & 66 & 33.2 & $1.18(0.86,1.63)$ & 22 & 36.1 & $0.88(0.51,1.53)$ & 88 & 33.8 & $1.03(0.79,1.36)$ \\
\hline
\end{tabular}

ancluding some ethnic minorities in China, such as Mongol and Manchu.

${ }^{\mathrm{b}}$ Including widowed, divorced/separated and unmarried.

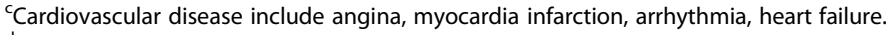

${ }^{\mathrm{d} C}$ Cerebrovascular disease include cerebral hemorrhage, cerebral infarction, subarachnoid hemorrhage, Transient Ischemic Attack.

${ }^{e}$ Chronic kidney disease nephritis, acute/chronic renal failure.

Italic and bold mean $P<0.05$; Bold only means $P<0.001$; CNY, China Yuan (1CNY $=0.161$ USD); Abbreviations: OR odds ratio, $95 \%$ CI $95 \%$ confidence interval.

approximately $23 \%$ when abdominal obesity was defined using a higher cut-off value, $15.1 \%$ when using $\mathrm{WC} \geq 102 \mathrm{~cm}$ for males and $\mathrm{WC} \geq 88 \mathrm{~cm}$ for females and $42.8 \%$ when using $\mathrm{WC} \geq 90 \mathrm{~cm}$ for males and $\mathrm{WC} \geq 80 \mathrm{~cm}$ for females. However, the higher cut-off value of WC likely underestimated the prevalence of abdominal obesity and MetS. In fact, our previous study reported that the prevalence of abdominal obesity was $48.6 \%$ in hypertensive women ten years ago in rural Liaoning province [23].

With regards to the prevalence of the individual metabolic disorders associated with MetS, the high prevalence of elevated blood pressure and increased fasting glucose was consistent with findings from another study of the Korean population aged $>60$ years, which reported a prevalence of $51.4 \%$ of participants with elevated blood pressure and $52.5 \%$ of participants with increased fasting glucose [24]. In contrast, a study held in the U.S. from 1999-2010 found that even though the incidence of MetS and related metabolic criteria had decreased, high numbers of participants with abdominal obesity $(56.1 \%)$ and low HDL-C (24.3\%) were still observed among Americans [25]. Similar findings were also observed in a study held in Malaysia [26]. Geographical variation and ethnic differences were relevant to the differences. We believe that demographic and socioeconomic factors may play a more important role in this difference.
In our study, we found a higher occurrence of MetS in women than in men, which was consistent with the findings of other studies [27]. Residents aged $>65$ years had a 1.64-fold (95\% CI: $1.40,1.91)$ greater risk of having MetS than those between 35-44 years old. As age advanced, individuals had greater risk of MetS because of greater risk of several other chronic diseases, which contribute to MetS, such as coronary heart disease, hypertension, diabetes and hyperlipidemia [28-30]. Our study had similar results to previous national surveys in that graduation from middle school correlated with lower risk of having MetS [31]. However, no relationship was found between those participants who had graduated from high school or higher education and the occurrence of MetS due to the small proportion of participants with a higher level of education in rural Chinese. We also found that moderate physical activity was correlated with lower prevalence of MetS, which may be due to the effect of physical activity on improving individual metabolic parameters [32]. However, vigorous physical activity did not correlate to MetS prevalence in our study because only $5.6 \%$ of participants took part in vigorous physical activity. Data showed that those who slept $\geq 9$ hours had an increased risk for MetS, which had been observed in previous studies [33]. There was a Ushaped association between sleep duration and MetS, which indicated that both short and long self-reported 
sleep durations were associated with an increased risk for developing diabetes [34]. An annual income $>20,000$ $\mathrm{CNY} /$ year was correlated with an increased risk of MetS in our study; however, the relationship between income and MetS or cardiovascular risks is still controversial in both developing and developed countries [26,35,36].

One interesting finding in our study was that participants who had more than one child seemed have greater risk of MetS than those who had only one or did not have children. We further analyzed this finding and found that participants with one or no children were significantly younger than those with more than one child ( $48.7 \pm 8.1$ vs. $57.3 \pm 10.6, P<0.001$ ). Only $3.1 \%$ of those with no or one or no children were $\geq 65$ years old, which was significantly lower than those with more than one child (23\%). Individuals with one or no children between the ages of $35-55$ years made up $77.2 \%$ of the participants, while individuals who had more than one child were mostly older than 55 years (60.1\%). This agespecific distribution was due to the one-child policy, which began in 1982 in China. In addition, females with more than one child had a higher incidence of MetS (50.8\% vs. $37.6 \%, P<0.001$ ), but the same trend was not observed in males (31.3\% vs. $31.5 \%)$. Previous studies have confirmed that obesity is increasing among pregnant women [37]. The more times a woman becomes pregnant, the more likely the woman is to be obese, which also increases the chance of having MetS. This difference probably warrants further study because it may imply that healthcare systems should pay attention to women who have or plan to have more than one child.

Surprisingly, smoking was correlated with a lower prevalence of MetS in rural Northeast China, while frequent consumption of beans or bean products and tea correlated with an increased risk of MetS. These results were inconsistent with the results of previous studies [38-40]. With the development of a healthy education program in rural areas over the past ten years, individuals have begun to pay attention to their health. Once participants knew they had hypertension or diabetes, they made efforts to rectify their metabolic disorders by changing their diet habits, quitting smoking and increasing their consumption of beans or bean products and tea. This change may result in a lower prevalence of smoking and increased consumption of beans and tea in individuals with MetS.

This study was performed in a representative sample of rural Chinese residents. Liaoning Province has an average population density of 297 people per square kilometer, wherein the majority of the population is settled in rural areas; thus, the findings were likely to be generally applicable to the rural Chinese population. However, some limitations of this study must be considered. First, our study was a cross-sectional study, which restricted the interpretation of the observed associations in terms of cause and effect. Longitudinal studies are required for further investigation of these findings. Second, the prevalence of MetS was based on a single assessment of blood samples, which may introduce error. In addition, although the researchers had been trained according to a standardized protocol of measurements, measurements at a single visit might lead to incorrect values for the anthropometric indexes.

\section{Conclusion}

This study was intended to update the prevalence rates of MetS in rural Northeast China and has shown a higher prevalence of MetS in rural areas than in some urban areas in China and other countries. The associated risk factors include age, sex, physical activity, having more than one child, annual income, sleep time, consumption of beans or bean products, education status, smoking and consumption of tea. It is our hope that the high prevalence of MetS will attract the attention of the government and lead them to address this severe situation.

\section{Abbreviations}

MetS: Metabolic syndrome; CNY: China yuan; WC: Waist circumference; BMI: Body mass index; FPG: Fasting plasma glucose; TC: Total cholesterol; LDL-C: Low-density lipoprotein cholesterol; HDL-C: High-density lipoprotein cholesterol; TG: Triglyceride; SBP: Systolic blood pressure; DBP: Diastolic blood pressure.

\section{Competing interests}

The authors declare that they have no competing interests.

\section{Authors' contributions}

SY analyzed the data and wrote the paper. SY, XG, HY enrolled participants and collected data. YS were responsible for designing the study and performing data analyses. All the authors contributed to the interpretation of data and critical revision and approval of the article.

\section{Acknowledgments}

This study was supported by grants from the "Twelfth Five-Year" project funds (National Science and Technology Support Program of China, Grant \# 2012BAJ18B02) and the Social Development Research Program of Liaoning Province (2013225089)

\section{Author details}

'Department of Cardiology, The First Hospital of China Medical University, 155 Nanjing North Street, Heping District, 110001 Shenyang, Liaoning, China. ${ }^{2}$ Department of Clinical Epidemiology, Shenjing Hospital of China Medical University, Shenyang, Liaoning, China.

Received: 10 May 2014 Accepted: 29 July 2014

Published: 26 August 2014

\section{References}

1. Misra A, Khurana L: Obesity and the metabolic syndrome in developing countries. J Clin Endocrinol Metab 2008, 93(Suppl 1):S9-S30.

2. Wang C, Wei D, Wang B, Zhang J, Zhang K, Ma M, Pan L, Yu T, Xue F, Shan G: Effect of lifestyle on the prevalence of the metabolic syndrome among farmers, migrants with Yi ethnicity and Han population in Sichuan province of China. Asia Pac J Clin Nutr 2010, 19(2):266-273.

3. Li G, de Courten M, Jiao S, Wang Y: Prevalence and characteristics of the metabolic syndrome among adults in Beijing, China. Asia Pac J Clin Nutr 2010, 19(1):98-102. 
4. Li JB, Wang X, Zhang JX, Gu P, Zhang X, Chen CX, Guo R, Wu M: Metabolic syndrome: prevalence and risk factors in southern China. J Int Med Res 2010, 38(3):1142-1148

5. Yang W, Reynolds K, Gu D, Chen J, He J: A comparison of two proposed definitions for metabolic syndrome in the Chinese adult population. Am J Med 2007, 334(3):184-189.

6. Zhang X, Sun Z, Zhang X, Zheng L, Li J, Liu S, Xu C, Li J, Zhao F, Hu D, Sun Y: Prevalence of metabolic syndrome in Han and Mongolian rural population with hypertension. J Int Med Res 2007, 35(5):597-599.

7. O'Brien E, Petrie J, Littler W, de Swiet M, Padfield PL, O'Malley K, Jamieson M, Altman D, Bland M, Atkins N: The British Hypertension Society protocol for the evaluation of automated and semi-automated blood pressure measuring devices with special reference to ambulatory systems. J Hypertens 1990, 8(7):607-619.

8. Grundy SM, Cleeman Jl, Daniels SR, Donato KA, Eckel RH, Franklin BA Gordon DJ, Krauss RM, Savage PJ, Smith SC Jr, Spertus JA, Costa F: Diagnosis and management of the metabolic syndrome. An American Heart Association/National Heart, Lung, and Blood Institute Scientific Statement. Executive summary. Cardiol Rev 2005, 13(6):322-327.

9. Hu G, Tuomilehto J, Silventoinen K, Barengo N, Jousilahti P: Joint effects of physical activity, body mass index, waist circumference and waist-to-hip ratio with the risk of cardiovascular disease among middle-aged Finnish men and women. Eur Heart J 2004, 25(24):2212-2219.

10. Panagiotakos DB, Pitsavos C, Chrysohoou C, Risvas G, Kontogianni MD, Zampelas A, Stefanadis C: Epidemiology of overweight and obesity in a Greek adult population: the ATTICA Study. Obes Res 2004, 12(12):1914-1920

11. Xu WH, Ruan XN, Fu XJ, Zhu QL, Zhang H, Bai Y, Wu HY, Zhou Y, Qiu H, Sun Q, Jiang QW, Yang LM, Gu JJ, Zhao GM: Prevalence of the metabolic syndrome in Pudong New Area of Shanghai using three proposed definitions among Chinese adults. BMC Public Health 2010, 10:246.

12. Cai H, Huang J, Xu G, Yang Z, Liu M, Mi Y, Liu W, Wang H, Qian D: Prevalence and determinants of metabolic syndrome among women in Chinese rural areas. PLoS One 2012, 7(5):e36936.

13. $\mathrm{Xi} \mathrm{B}, \mathrm{He} \mathrm{D}, \mathrm{Hu} Y$, Zhou D: Prevalence of metabolic syndrome and its influencing factors among the Chinese adults: the China Health and Nutrition Survey in 2009. Prev Med 2013, 57(6):867-871.

14. He J, Gu D, Reynolds K, Wu X, Muntner P, Zhao J, Chen J, Liu D, Mo J, Whelton PK, InterASIA Collaborative Group: Serum total and lipoprotein cholesterol levels and awareness, treatment, and control of hypercholesterolemia in China. Circulation 2004, 110(4):405-411.

15. Zhang WH, Xue P, Yao MY, Chang HM, Wu Y, Zhang L: Prevalence of metabolic syndrome and its relationship with physical activity in suburban Beijing, China. Ann Nutr Metab 2013, 63(4):298-304.

16. Wang GR, Li L, Pan YH, Tian GD, Lin WL, Li Z, Chen ZY, Gong YL, Kikano GE, Stange KC, Ni KL, Berger NA: Prevalence of metabolic syndrome among urban community residents in China. BMC Public Health 2013, 13:599.

17. Li J, Shi YM, Yan JH, Xu W, Weng JP: The prevalence and risk factors of metabolic syndrome among adult residents in Guangdong and Jiangsu provinces in China. Zhonghua Nei Ke Za Zhi 2013, 52(8):659-663.

18. Zuo H, Shi Z, Hu X, Wu M, Guo Z, Hussain A: Prevalence of metabolic syndrome and factors associated with its components in Chinese adults. Metabolism 2009, 58(8):1102-1108.

19. Ford ES, Giles WH, Dietz WH: Prevalence of the metabolic syndrome among US adults: findings from the third National Health and Nutrition Examination Survey. JAMA 2002, 287(3):356-359.

20. Riediger ND, Clara I: Prevalence of metabolic syndrome in the Canadian adult population. CMAJ 2011, 183(15):E1127-E1134.

21. Yip W, Wong TY, Jonas JB, Zheng Y, Lamoureux EL, Nangia V, Sabanayagam C: Prevalence, awareness, and control of hypertension among Asian Indians living in urban Singapore and rural India. J Hypertens 2013, 31(8):1539-1546.

22. Basu S, Millett C: Social epidemiology of hypertension in middle-income countries: determinants of prevalence, diagnosis, treatment, and control in the WHO SAGE study. Hypertension 2013, 62(1):18-26.

23. Zhang X, Sun Z, Zhang X, Zheng L, Liu S, Xu C, Li J, Zhao F, Li J, Hu D, Sun $Y$ : Prevalence and associated factors of overweight and obesity in a Chinese rural population. Obesity (Silver Spring) 2008, 16(1):168-171.

24. Lim ES, Ko YK, Ban KO: Prevalence and risk factors of metabolic syndrome in the Korean population-Korean National Health Insurance Corporation Survey 2008. J Adv Nurs 2013, 69(7):1549-1561.
25. Beltrán-Sánchez H, Harhay MO, Harhay MM, McElligott S: Prevalence and trends of metabolic syndrome in the adult U.S. population, 1999-2010. J Am Coll Cardiol 2013, 62(8):697-703.

26. Shariff ZM, Sulaiman N, Jalil RA, Yen WC, Yaw YH, Taib MN, Kandiah M, Lin KG: Food insecurity and the metabolic syndrome among women from low income communities in Malaysia. Asia Pac J Clin Nutr 2014, 23(1):138-147

27. Ferguson TS, Tulloch-Reid MK, Younger NO, Knight-Madden JM, SammsVaughan M, Ashley D, Van den Broeck J, Wilks RJ: Prevalence of metabolic syndrome and its components in relaation to socioeconomic status among Jamaican young adults: A cross-sectional study. BMC Public Health 2010, 10:307.

28. Laclaustra M, Ordoñez B, Leon M, Andres EM, Cordero A, Pascual-Calleja I, Grima A, Luengo E, Alegria E, Pocovi M, Civeira F, Casasnovas-Lenguas JA: Metabolic syndrome and coronary heart disease among Spanish male workers: a case-control study of MESYAS. Nutr Metab Cardiovasc Dis 2012, 22(6):510-516

29. Dominguez $\sqcup$, Barbagallo M: The cardiometabolic syndrome and sarcopenic obesity in older persons. J Cardiometab Syndr 2007, 2(3):183-189.

30. Dey DK, Lissner L: Obesity in 70-year-old subjects as a risk factor for 15-year coronary heart disease incidence. Obes Res 2003, 11(7):817-827.

31. Erem C, Hacihasanoglu A, Deger O, Topbaş M, Hosver I, Ersoz HO, Can G: Prevalence of metabolic syndrome and associated risk factors among Turkish adults: Trabzon MetS study. Endocrine 2008, 33(1):9-20.

32. Bergström G, Behre C, Schmidt C: Increased leisure-time physical activity is associated with lower prevalence of the metabolic syndrome in 64-year old women with impaired glucose tolerance. Angiology 2012, 63(4):297-301

33. Choi KM, Lee JS, Park HS, Baik SH, Choi DS, Kim SM: Relationship between sleep duration and the metabolic syndrome:Korean Nation Health and Nutrition Survey 2001. Int J Obes (Lond) 2008, 32(7):1091-1097.

34. Gottlieb DJ, Punjabi NM, Newman AB, Resnick HE, Redline S, Baldwin CM, Nieto FJ: Association of sleep time with diabetes mellitus and impaired glucose tolerance. Arch Intern Med 2005, 165(8):863-867.

35. Dallongeville J, Cottel D, Ferrières J, Arveiler D, Bingham A, Ruidavets JB, Haas $B$, Ducimetière $P$, Amouyel $P$ : Household income is associated with the risk of metabolic syndrome in a sex-specific manner. Diabetes Care 2005, 28(2):409-415.

36. Mangat C, Goel NK, Walia DK, Agarwal N, Sharma MK, Kaur J, Singh R, Singh G: Metabolic syndrome: a challenging health issue in highly urbanized Union Territory of north India. Diabetol Metab Syndr 2010, 2:19.

37. Fisher SC, Kim SY, Sharma AJ, Rochat R, Morrow B: Is obesity still increasing among pregnant women? Prepregnancy obesity trends in 20 states, 2003-2009. Prev Med 2013, 56(6):372-378

38. Hosseinpour-Niazi S, Mirmiran P, Amiri Z, Hosseini-Esfahani F, Shakeri N, Azizi F: Legume intake is inversely associated with metabolic syndrome in adults. Arch Iran Med 2012, 15(9):538-544.

39. Vernarelli JA, Lambert JD: Tea consumption is inversely associated with weight status and other markers for metabolic syndrome in US adults. Eur J Nutr 2013, 52(3):1039-1048.

40. Chang CS, Chang YF, Liu PY, Chen CY, Tsai YS, Wu CH: Smoking, habitual tea drinking and metabolic syndrome in elderly men living in rural community: the Tianliao old people (TOP) study 02. PLOS One 2012, 7(6):e38874

doi:10.1186/1471-2458-14-877

Cite this article as: Yu et al:: An update on the prevalence of metabolic syndrome and its associated factors in rural northeast China. BMC Public Health 2014 14:877. 